\title{
Apical periodontitis and glycemic control in type 2 diabetic patients: Cross-sectional study
}

\author{
Flor de Liz Pérez-Losada ${ }^{1}$, José López-López ${ }^{2}$, Jenifer Martín-González ${ }^{3}$, Enric Jané-Salas ${ }^{4}$, Juan J. \\ Segura-Egea ${ }^{5}$, Albert Estrugo-Devesa ${ }^{6}$
}

${ }^{1}$ DDS, Doctoral fellow, Department of Odontostomatology, Faculty of Medicine and Health Sciences, University of Barcelona. L'Hospitalet de Llobregat, Barcelona, Spain

${ }^{2} \mathrm{MD}$, DDS, PhD, Professor, Department of Odontostomatology, Faculty of Medicine and Health Sciences, University of Barcelona- Dental Hospital, University of Barcelona, L'Hospitalet de Llobregat, Barcelona, Spain

${ }^{3} \mathrm{DDS}, \mathrm{PhD}$, Associate Professor, Division of Endodontics, Department of Stomatology, School of Dentistry, University of Sevilla, Sevilla, Spain

${ }^{4} \mathrm{MD}$, DDS, PhD, Professor, Department of Odontostomatology, Faculty of Medicine and Health Sciences, University of Barcelona- Dental Hospital, University of Barcelona, L'Hospitalet de Llobregat, Barcelona, Spain

${ }^{5}$ MD, DDS, PhD, Professor, Division of Endodontics, Department of Stomatology, School of Dentistry, University of Sevilla, Sevilla, Spain

${ }^{6} \mathrm{MD}$, DDS, PhD, Associate Professor, Department of Odontostomatology, Faculty of Medicine and Health Sciences, University of Barcelona- Dental Hospital, University of Barcelona, L'Hospitalet de Llobregat, Barcelona, Spain

\section{Correspondence:}

Division of Endodonctics

Department of Stomatology

School of Dentistry

University of Sevilla

C/ Avicena s/n, 41009-Sevilla, Spain

segurajj@us.es

Pérez-Losada F, López-López J, Martín-González J, Jané-Salas E, Segura-Egea JJ, Estrugo-Devesa A. Apical periodontitis and glycemic control in type 2 diabetic patients: Cross-sectional study. J Clin Exp Dent. 2020;12(10):e964-71.

Received: 11/04/2020

Accepted: 14/05/2020

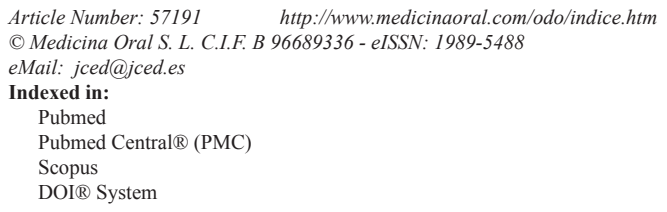

\begin{abstract}
Background: The objective of this study was to analyze the possible relationship between the glycemic control and the prevalence of apical periodontitis in type 2 diabetic patients. The null hypothesis was that apical periodontitis is not associated with glycemic control.

Material and Methods: In a cross-sectional design, the radiographic records of 216 type 2 diabetic patients (65.0 \pm 10.7 years), 117 men $(54.2 \%)$ and women $(45.8 \%)$, were examined. Glycated hemoglobin (HbA1c) was used to assess glycemic control, considering an $\mathrm{HbA} 1 \mathrm{c}$ level $<6.5 \%$ as well-controlled diabetes. Apical periodontitis was diagnosed as radiolucent periapical lesions using the periapical index score. The Student $t$ test, chi-square test, and logistic regression analysis were used in the statistical analysis.

Results: The average HbAlc value was $7.0 \pm 2.2 \%$. Forty seven $(21.8 \%$ ) had HbAlc levels under $6.5 \%$ (mean \pm $\mathrm{SD}=6.0 \pm 2.2 \%$ ), being considered well-controlled patients, and $169(78.2 \%)$ had an $\mathrm{HbAlc}$ level $\geq 6.5 \%$ (mean \pm $\mathrm{SD}=7.8 \pm 2.24 \%$ ), being considered poor controlled patients. Forty four per cent of diabetics had apical periodontitis, $12.5 \%$ had root-filled teeth, and $52.3 \%$ had root filled teeth with radiolucent periapical lesions. No significant differences were observed in any of these three variables between patients with good or poor glycemic control. In the multivariate logistic regression analysis the presence of radiolucent periapical lesions in at least one tooth did not correlate significantly with $\mathrm{HbAlc}$ levels $(\mathrm{OR}=1.4 ; 95 \%$ C.I. $=0.70-3.09 ; p=0.31)$.
\end{abstract}


Conclusions: The results reveal no association of glycemic control with the prevalence of apical periodontitis or root canal treatment in diabetic patients.

Key words: Apical periodontitis, diabetes mellitus, endodontic medicine, glycated haemoglobin.

\section{Introduction}

Diabetes mellitus (DM) is a group of metabolic diseases affecting the metabolism of carbohydrates, lipids and proteins, with hyperglycemia, as a result of a deficiency in insulin secretion, lack of insulin action or both (1). Chronic hyperglycemia is associated with long standing damage, dysfunction and failure of diverse organs, especially eyes, kidneys, nerves, heart and blood vessels (2). Glycated hemoglobin (HbA1c) has been used as the gold standard for the control of diabetic patients. This test measures the average glycaemia of the last 2-3 months, allowing the assessment of the effectiveness of the patient's treatment (3). The American Association of Clinical Endocrinologist considers $\mathrm{HbA} 1 \mathrm{c} \geq 6.5 \%$ as a goal in the optimal control of diabetic patients (4).

Apical periodontitis (AP) is an inflammatory lesion around the root apex consecutive to bacterial infection of the pulp canal system (5). A periapical radiolucent lesion (PRL) in the radiography is the characteristic sign of chronic apical periodontitis (6). However, AP must be considered not exclusively a locally process. The inflammatory cytokines released in inflamed periapical tissues, such as IL- $1 \beta$, IL-6, IL-8, and TNF- $\alpha$, may reach the systemic circulation inducing or perpetuating an elevated chronic systemic inflammatory status (7-9).

Several studies have reported results supporting a relationship between the prevalence AP and diabetes (10-17). Moreover, several systematic reviews and meta-analyses have found significant association between the outcome of endodontic treatment and diabetes (1820). Nevertheless, few studies have investigated the possible relationship between endodontic infections and glycemic control in diabetic patients. Poorly controlled diabetics tend to develop periapical radiolucencies during endodontic treatment (21), and chronic apical periodontitis has been linked to an increase in blood glucose in diabetic patients (22). Two studies have found correlation between higher prevalence of AP and poor glycemic control in diabetic patients $(17,23)$. Vice versa, it has been found a higher percentage of reduction of periradicular radiolucencies in patients with lower glycaemia (24). However, there are no definitive data on the association between blood glucose levels and the prevalence of AP in diabetic patients.

The aim of this study was to analyze the possible relationship between the prevalence of AP, diagnosed as a periapical radiolucent lesion (PRL), and the glycemic control, assessed by HbAlc levels, of type 2 diabetic pa- tients. The null hypothesis was that AP is not associated with glycemic control in diabetic patients.

\section{Material and Methods}

An observational descriptive cross-sectional study was designed. The study was approved by the ethical committee of the Dental Clinic of the University of Barcelona (Barcelona, Spain), reference number 10/31/2018. The investigation was conducted following the World Medical Association-Declaration of Helsinki. All participants signed the written informed consent.

-Patients

Participants were recruited among patients presenting consecutively seeking routine dental care (not emergency care) at the Dental Hospital (Faculty of Medicine and Health Sciences, Dentistry, University of Barcelona, HOUB) and from a primary health center (ABS Sta. Eulalia Sud, L'Hospitalet de Llobregat, Barcelona), during the years 2013 through 2016. All type 2 diabetic patients, diagnosed according to the current criteria for the diagnosis of diabetes (25), were asked to voluntarily participate. The following inclusion criteria were used: over 18 years of age, with more than seven teeth remaining, with records of $\mathrm{HbAlc}$ levels in the last week, who accepted a radiological examination. The exclusion criteria were the following: less than 18 years of age, less than eight remaining teeth, unknown $\mathrm{HbA} 1 \mathrm{c}$ levels, or no acceptance of the radiological examination. Two hundred and forty four diabetic patients met the inclusion/exclusion criteria and were asked to participate in the study, but only $216(65.0 \pm 10.7$ years), 117 men (54.2\%) and women (45.8\%) accepted to be included in the study and signed the written informed consent.

Data was collected from the clinical histories, eliciting information on medical and dental history, about coronary heart disease, the most recent measurement of HbAlc levels, smoking status, alcohol consumption assessed as intake of Standard Beverage Unit (8-13 grs of pure alcohol) by day, and periodontal status assessed using the criteria of Machtei et al. (26).

-Assessment of glycemic control

The status of the metabolic control of the diabetic patients was achieved by checking the values of the glycosylated hemoglobin $(\mathrm{HbAlc})$. The blood test had to be performed less than a month prior to the study visit. Adequate glycemic control was defined as $\mathrm{HbAlc}<$ $6.5 \%(25)$. 
-Radiological examination and periapical status assessment

Radiographic periapical status was diagnosed on the basis of examination of digital panoramic radiographs of the jaws. Two qualified radiologic technicians, with more than 10 years of experience in their field, performed the OPG using a digital orthopantomogram (Promax, Planmeca, class 1, type B, $80 \mathrm{KHz}$; Planmeca, Helsinki, Finland).

All teeth, excluding third molars, were recorded. Teeth were categorized as root filled teeth if they had been filled with a radiopaque material in the root canal(s). For each subject the number of teeth present, the number and location of root-filled teeth, and the number and location of teeth having identifiable radiolucent periapical lesions were recorded.

The periapical status was assessed using 'Periapical Index' (PAI) score (27). A score greater than 2 (PAI $\geq 3$ ) was considered to be a sign of AP. The worst score of all roots was taken to represent the PAI score for multi-rooted teeth.

-Observers' calibration

Three observers with a broad clinical experience in endodontics assessed the radiographs (AED, JLL and FPL); disagreements were weighted by JSE and JMG. Before evaluation, the observers participated in a calibration course for PAI system, which consisted of 100 radiographic images of teeth, some root-filled and some not, kindly provided by Dr. Ørstavik (Ørstvik et al. 1986). Each tooth was assigned to one of the PAI scores by using visual references (also provided by Dr. Ørstavik) for the 5 categories within the scale. After scoring the teeth, the results were compared to a "gold standard atlas", and a Cohen Kappa was calculated (0.78-0.89). Intra-observer reproducibility was evaluated for each examiner. Every observer scored the panoramic radiographs of 20 patients (10 of each group, randomly selected). Then, one month after this first examination, the observer was recalibrated in the PAI system and repeated the scoring of the radiographs of the same 20 patients. The intra-observer agreement test on PAI scores on the 20 patients produced a Cohen's Kappa ranging $0.80-0.91$.

Intra-observers reproducibility was also determined comparing the PAI scores on the 20 radiographs provided by each observer. The agreement test produced a Cohen's Kappa ranging 0.78 - 0.94. The Cohen's Kappa for inter-observers variability ranged $0.83-0.90$. The consensus radiographic standard was the simultaneous interpretation by the three examiners of the panoramic radiograph of each patient.

-Statistical analysis

Minimal sample size was calculated using "Sample size and power calculator", v7.12 software (https:/www. imim.cat/ofertadeserveis/software-public/granmo/). Ac- cepting an alpha risk of 0.05 and a beta risk of 0.2 in a two-sided test, 204 subjects are necessary in the observed group to recognize a difference greater than or equal to 0.1 units. A proportion in the reference group has been estimated to be 0.35 . It has been anticipated a drop-out rate of $10 \%$. Post-hoc power analysis has been performed using the same software.

The primary data was introduced into an Excel spreadsheet (Microsoft Corp, Redmond, WA). SPSS (version 11; SPSS, Inc., Chicago, IL) was used for the statistical analysis. Data is presented as media \pm standard deviation. A t-test and X2 test were used to determine the differences between groups. A logistic regression analysis was performed to measure the strength of the association between the HbA1c levels and the presence of periapical radiolucencies, adjusting the presence of co-variables. A $p$ value $<0.05$ was considered to be statistically significant.

\section{Results}

The characteristics and dental status of the type 2 diabetic patients are described in Table 1 . The mean number

Table 1: Characteristics and dental status of diabetic patients $(\mathrm{n}=$ 216) included in the study. Results are expressed as mean \pm standard deviation.

\begin{tabular}{|l|c|}
\hline Characteristic & Value \\
\hline Age (y) & $65.0 \pm 10.7$ \\
\hline Gender & $117(54.2 \%)$ \\
\hline Male & $99(45.8 \%)$ \\
\hline Female & \\
\hline Smoking habits & $60(27.8 \%)$ \\
\hline Yes* & $156(72.2 \%)$ \\
\hline No & \\
\hline Alcohol consumption & $52(24.1 \%)$ \\
\hline Yes** & $164(75.9 \%)$ \\
\hline No & \\
\hline Coronary Heart Disease & $150(69.4 \%)$ \\
\hline Yes & $66(30.6 \%)$ \\
\hline No & $20.9 \pm 6.6$ \\
\hline Number of teeth & $0.8 \pm 1.3$ \\
\hline Number of RFT & $0.5 \pm 0.4$ \\
\hline Number of teeth with RPL & \\
\hline Periodontal disease & $130(60.2 \%)$ \\
\hline Yes & $86(39.8 \%)$ \\
\hline No & \\
\hline HbAlc levels $(\%)$ & \\
\hline RFT rootfled & \\
\hline
\end{tabular}

RFT: root-filled teeth.

RPL: radiolucent periapical lesions.

*Smoker or former smoker.

**More than 2 Standard Beverage Unit (8- 13 grs of pure alcohol) / day. 
of teeth was $20.9 \pm 6.6$, and the average number of teeth with radiolucent periapical lesion was $0.5 \pm 0.4$. The mean number of RFT per patient was $0.8 \pm 1.3$. Sixty patients $(27.8 \%)$ were smoker or former smoker, 52 $(24.1 \%)$ were consumers of alcoholic beverages, 150 (69.4\%) had coronary heart disease, and 130 (60.2\%) had periodontal disease. The average glycosylated hemoglobin $(\mathrm{HbA} 1 \mathrm{c})$ value was $7.0 \pm 2.2$ per cent.

Diabetic patients were classified dichotomously according to their glycemic control (Table 2). Forty seven (21.8\%) had HbA1c levels under 6.5\% (mean $\pm \mathrm{SD}=$ $6.0 \pm 2.2 \%$ ), being considered well-controlled patients. On the contrary, $169(78.2 \%)$ had an HbAlc level $\geq$ $6.5 \%$ (mean $\pm \mathrm{SD}=7.8 \pm 2.24 \%$ ), being considered poor controlled patients. No significant differences were found between patients with good or poor glycemic control regarding age, gender, number of teeth, smoking habits, alcohol consumption, coronary heart disease or periodontal status $(p>0.05)$. Forty four per cent of diabetic patients showed at least 1 radiolucent periapical lesion (RPL), $12.5 \%$ had at least 1 RFT, and $52.3 \%$ had at least 1 root-filled tooth with RPL (Table 3 ). There was no significant difference between patients with good or poor glycemic control in the number of teeth with periapical lesions $(\mathrm{OR}=1.74 ; 95 \%$ C.I. $=0.89-3.42 ; p=$ $0.10)$. The percentage of good-controlled patients with at least 1 root-filled tooth with RPL was $34.0 \%$, whereas amongst poor-controlled patients this percentage was $47.3 \%(p>0.05)$. The number of RFT $(\mathrm{OR}=1.26 ; 95 \%$ C.I. $=0.45-3.52 ; p=0.66)$, and the number of RFT with periapical lesions $(\mathrm{OR}=1.33 ; 95 \%$ C.I. $=0.69-$ $2.53 ; p=0.39$ ) was not associated to HbAlc levesl.

To further investigate whether HbA1c levels were related to endodontic variables, multivariate logistic regressions were run with age, gender, smoking habits, alcohol consumption, number of teeth, number of RFT, number of RFT with AP, periodontal status, and periapical status as independent explanatory variables, and $\mathrm{HbA} 1 \mathrm{c}$ levels as dependent variable $(0=\mathrm{HbA} 1 \mathrm{c}<6.5 \% ; 1=\mathrm{HbA} 1 \mathrm{c}$ $\geq 6.5 \%$ ) (Table 4 ). In the multivariate logistic regression

Table 2: Characteristics and dental status of diabetic patients after classifying them according to their glycemic control (HbAlc levels). Results are expressed as mean \pm standard deviation.

\begin{tabular}{|c|c|c|c|}
\hline & Good controlled & Poor controlled & $p$ \\
\hline & $\mathrm{HbA} 1 \mathrm{c}<6.5 \%$ & $\mathrm{HbA} 1 \mathrm{c} \geq 6.5 \%$ & \\
\hline Patients & $47(21.8 \%)$ & $169(78.2 \%)$ & $>0.05$ \\
\hline HbAlc levels & $6.0 \pm 2.2$ & $7.8 \pm 2.2$ & $<0.0001$ \\
\hline Age (y) & $64.5 \pm 10.6$ & $63.9 \pm 10.7$ & $>0.05$ \\
\hline \multicolumn{4}{|l|}{ Gender } \\
\hline Male & $25(53.2 \%)$ & $92(54.4 \%)$ & $>0.05$ \\
\hline Female & $22(46.8 \%)$ & $77(45.6 \%)$ & $>0.05$ \\
\hline \multicolumn{4}{|l|}{ Smoking habits } \\
\hline Yes* & $14(29.8 \%)$ & $46(27.2 \%)$ & $>0.05$ \\
\hline No & $33(70.2 \%)$ & $123(72.8 \%)$ & $>0.05$ \\
\hline \multicolumn{4}{|l|}{ Alcohol consumption } \\
\hline Yes $^{* *}$ & $9(19.1 \%)$ & $43(25.4 \%)$ & $>0.05$ \\
\hline No & $38(80.9 \%)$ & $126(74.6 \%)$ & $>0.05$ \\
\hline \multicolumn{4}{|l|}{ Coronary Heart Disease } \\
\hline Yes & $30(63.8 \%)$ & $120(71.0 \%)$ & $>0.05$ \\
\hline No & $17(36.2 \%)$ & $49(29.0 \%)$ & $>0.05$ \\
\hline Number of teeth & $20.1 \pm 7.2$ & $21.2 \pm 6.3$ & $>0.05$ \\
\hline Number of RFT & $0.5 \pm 1.1$ & $0.9 \pm 1.4$ & $>0.05$ \\
\hline Number of teeth with RPL & $0.4 \pm 0.4$ & $0.5 \pm 0.4$ & $>0.05$ \\
\hline \multicolumn{4}{|l|}{ Periodontal disease } \\
\hline Yes & $25(53.2 \%)$ & $105(62.1 \%)$ & $>0.05$ \\
\hline No & $22(46.8 \%)$ & $64(37.9 \%)$ & $>0.05$ \\
\hline
\end{tabular}

RFT: root-filled teeth.

RPL: radiolucent periapical lesions.

*Smoker or former smoker.

**More than 2 Standard Beverage Unit (8- 13 grs of pure alcohol) / day. 
Table 3: Univariate logistic regression analysis of the association of the independent variables a) presence of radiolucent periapical lesions (RPL), b) root filled teeth (RFT), and c) RFT with RPL (RFT-RPL), with the dependent variable "HbAlc levels ", dichotomized as $<6.5 \%$ (GC) or $\geq 6.5 \%$ $(\mathrm{PC})$.

\begin{tabular}{|l|c|c|c|}
\hline & GC & PC & TOTAL \\
\hline & $($ HbAlc $<6.5 \%)$ & $($ HbAlc $\geq 6.5 \%)$ & \\
\hline At least one RPL & $16(34.0 \%)$ & $80(47.3 \%)$ & $96(44.4 \%)$ \\
\hline No RPL & $31(65.9 \%)$ & $89(52.7 \%)$ & $120(55.5 \%)$ \\
\hline Total & 47 & 169 & 216 \\
\hline Odds ratio & 1.0 & $1.74 *$ & \\
\hline C.I. 95\% & & $0.89-3.42$ & \\
\hline At least one RFT & $5(10.6 \%)$ & $22(13.0 \%)$ & $27(12.5 \%)$ \\
\hline No RFT & $42(89.3 \%)$ & $147(86.9 \%)$ & $189(87.5 \%)$ \\
\hline Total & 47 & 169 & 216 \\
\hline Odds ratio & 1.0 & $1.26 *$ & \\
\hline C.I. 95\% & & $0.45-3.52$ & \\
\hline At least one RFT-RPL & $22(46.8 \%)$ & $91(53.8 \%)$ & $113(52.3 \%)$ \\
\hline No RPL & $25(53.1 \%)$ & $78(46.1 \%)$ & $103(47.6 \%)$ \\
\hline Total & 47 & 169 & 216 \\
\hline Odds ratio & 1.0 & $1.33 *$ & \\
\hline C.I. 95\% & & $0.69-2.53$ & \\
\hline
\end{tabular}

$* p>0.05$;

GC: good controlled: PC: poor controlled.

RFT: root-filled teeth.

RPL: radiolucent periapical lesion.

Table 4: Multivariate logistic regression analyse of the influence of the independent variables age, gender $(0=$ women, $1=$ male $)$, smoking $(0=$ non-smoker, $1=$ smoker $)$, alcohol consumption $(0=<2 \mathrm{SBU}, 1=>2 \mathrm{SBU})$, number of teeth, number of RFT, number of RFT with AP, periodontal disease $(0=$ absent, $1=$ present $)$, and apical periodontitis $(0=$ no tooth with radiolucent periapical lesion, $1=$ one or more tooth with radiolucent periapical lesion), on the dependent variable "HbAlc levels" $(0=\mathrm{HbAlc}<6.5 \% ; 1=$ $\mathrm{HbA} 1 \mathrm{c} \geq 6.5 \%)$.

\begin{tabular}{|c|c|c|c|c|c|}
\hline Explanatory variable & B & $p$ & Odds Ratio & $\begin{array}{c}\text { C. I. 95\% Inf. } \\
\text { Limit }\end{array}$ & $\begin{array}{c}\text { C. I. 95\% Sup. } \\
\text { Limit }\end{array}$ \\
\hline Age & -0.0035 & 0.8430 & 0.9965 & 0.9629 & 1.0314 \\
\hline Gender & 0.0302 & 0.9335 & 1.0306 & 0.5074 & 2.0932 \\
\hline Smoking & -0.4323 & 0.3326 & 0.6490 & 0.2707 & 1.5561 \\
\hline Alcohol & 0.4425 & 0.3693 & 1.5566 & 0.5925 & 4.0895 \\
\hline No. of teeth & 0.0387 & 0.1570 & 1.0394 & 0.9852 & 1.0966 \\
\hline No. of RFT & 0.6188 & 0.1274 & 1.8568 & 0.8380 & 4.1140 \\
\hline Np. of RFT + AP & -0.3457 & 0.6136 & 0.7077 & 0.1849 & 2.7082 \\
\hline Periodontal disease & 0.5317 & 0.1497 & 1.7018 & 0.8256 & 3.5080 \\
\hline Apical periodontitis & 0.3825 & 0.3145 & 1.4660 & 0.6957 & 3.0892 \\
\hline
\end{tabular}

Overall model fit: Chi Square $=8.79 ; \mathrm{df}=9 ; p=0.46$

RFT: root filled teeth; AP: apical periodontitis.

$\mathrm{SBU}=$ Standard Beverage Unit, equivalent to $8-13$ grs of pure alcohol / day.

analysis including all the above factors as covariates, the presence of RPL in at least one tooth did not correlate significantly with $\mathrm{HbA} 1 \mathrm{c}$ levels $(\mathrm{OR}=1.4 ; 95 \%$ C.I. $=$ $0.70-3.09 ; p=0.31)$.

\section{Discussion}

In this observational cross-sectional study, the possible association between the prevalence of RPL and glycemic control in diabetic patients has been investigated. 
The results reveal no higher prevalence of RPL in poor controlled type 2 diabetic patients, with HbA1c levels $\geq 6.5 \%(p=0.31)$. Nor has an association been found between the level of $\mathrm{HbAl}$ c and the prevalence of RCT. The recruitment method of the patients was similar to that used in previous studies $(10,14,23,28)$ : subjects presenting consecutively seeking routine dental care (not emergency care) at the dental service of the Faculty of Dentistry. Diabetes was diagnosed according to the current criteria for the diagnosis of diabetes (25). Glycated hemoglobin levels ( $\mathrm{HbAl} \mathrm{c})$ were used to assess glycemic control, providing an accurate measure of blood glucose levels in the previous 30-90 days (4). When blood glucose levels are high, glucose and other sugars slowly bind covalently and non-enzymatically to hemoglobin (glycosylation). The rate of formation of $\mathrm{HbAlc}$ is directly proportional to blood glucose concentrations.

The prevalence of AP was assesses using panoramic radiographs and the Periapical Index (27), as other studies have used previously (29-35). Observer calibration was performed according to PAI score system, obtaining adequate Kappa values for intra-observer and inter-observer reproducibility (27). Panoramic radiographs showed high specificity and positive predictive value diagnosing apical periodontitis (36), can be obtained with convenience and speed, and have the advantage of producing an average patient exposure of only $4.1 \mu \mathrm{Sv}$ (37).

In the present study, the percentage of diabetics with good glycemic control was very low. Only 47 diabetic patients $(22 \%)$ had well-controlled HbAlc levels $(<$ 6.5\%). Sanchez-Domínguez et al. (23) found a similar proportion $(28.9 \%)$, but other studies have reported higher percentages of well-controlled diabetics $(17,40)$. This lower percentage of well-controlled diabetics could explain, at least in part, the differences in the results of the present study with those previously performed $(17,23,40)$. It may also have influenced the non-significant findings of the present study, since the high percentage of poorly controlled diabetic patients limits the statistical power to detect significant differences between the proportions of RPL, RFT and RFT with RPL in both groups. Before starting this study, the researchers calculated that they would need a minimal sample size of 204 participants to see a statistically significant difference between poor- and good-controlled diabetic patients. The high percentage of poor-controlled diabetics may also have caused that age, gender, smoking habits, alcohol consumption, coronary heart disease, number of teeth, number of root-filled teeth, or number of teeth with RPLs did not show statistical association with HbAlc levels $(p>0.05)$. However, other studies have also found no association between these variables and glycemic control in diabetic patients (23).

The present results show that $44.4 \%$ of diabetic patients had AP, diagnosed as RPL, in one or more teeth.
Some previous studies have found higher prevalence of periapical lesions in diabetics $(10,28,38)$, but other have reported minor prevalence values $(14,17,39)$. The prevalence of at least one RPL in well-controlled diabetics did not significantly differ from that observed in poor-controlled diabetic patients $(\mathrm{OR}=1.74 ; p=0.10)$. The high percentage of poorly controlled diabetics have decreased the power of the study. Accepting an alpha risk of 0.05 in a two-sided test with 169 poor-controlled patients and 47 good-controlled diabetics, the statistical power is only $37.4 \%$ to recognize as statistically significant the difference from $47 \%$ of prevalence of RPL in the first group to $34 \%$ in the second group.

Only three epidemiological studies have investigated the potential association of periapical inflammation with the glycemic control in diabetics, two using digital panoramic radiographs and the PAI system score $(17,23)$, and another (40) using CBCT with a voxel size of 0.200 $\mathrm{mm}$ and the cone beam computed tomography periapical index (CBCTPAI) (41). The study conducted in 2015 included 83 diabetic patients and used the same HbAlc threshold (6.5\%) to determine the good or poor glycemic control, reporting an OR $=3.6(95 \%$ C.I $=$ $1.0-13.0 ; p=0.049$ ), calculated through multivariate logistic regression analysis, concluding that $\mathrm{HbAlc}$ levels of diabetic patients are associated with periapical status (23). Smadi (17), including 145 diabetic patients and using a $7 \% \mathrm{HbA} 1 \mathrm{c}$ level to establish the degree of glycemic control, found that poor controlled diabetics showed higher prevalence of AP lesions (18.3\%) compared with well-controlled diabetic patients $(9.21 \%)(p$ $=0.001)$. Moreover, poor controlled diabetic showed higher prevalence of RFT with AP (32.0\%) compared to well-controlled patients $(21.8 \%)(p=0.02)$, concluding that a poor glycemic control may be associated with a higher prevalence of AP and increased rate of endodontic failures. The third study analysed only the periapical status of RFT (40), including a small sample (43 diabetic patients) and assessing the periapical status using the CBCTPAI index (41). In this study the HbAlc level to assess glycemic control was $6.5 \%$, finding $69.6 \%$ of we11-controlled diabetics, and concluding that there were no differences in the periapical status of RFT between well- and poor-controlled diabetics. The characteristics of the samples, the different threshold of $\mathrm{HbAlc}$ values, the different proportions of well- and poor-controlled diabetics, and the radiological technique and criteria used to diagnose periapical lesions may explain the observed differences amongst these studies and the present results.

In accordance with the study of Sisli (40), the results of the present study did not find association between root canal treatment (RCT) outcome and glycemic control. The prevalence of at least 1 RFT with RPL was similar in well- and poor-controlled diabetic patients $(p>0.05)$. 
However, the total prevalence of RPL associated to endodontically treated teeth was high $(52.3 \%)$. Other previous studies have found similar percentages $(10,23,28)$. Scientific evidence support the relationship between poor RCT outcome and diabetes (18). Two systematic reviews with meta-analysis have shown that diabetics are more likely to have periapical radiolucent lesions in their $\mathrm{RFT}(\mathrm{OR}=1.4 ; 95 \% \mathrm{CI}=1.1$ to $1.8 ; p=0.006)(20)$ and that they are more likely to lose RFT $(\mathrm{OR}=2.4$; $95 \% \mathrm{CI}=1.5-3.9 ; p=0.0001)(19)$.

The possible relationship between glycemic control and endodontic infection has been also investigated in animal models. It has been demonstrated that diabetes enhance the development of periradicular lesions in rats (42), and hyperglycaemia adversely affects pulp healing in rats after pulp capping with MTA (43). Moreover, HbAlc in diabetic rats is increased by oral infections (43).

The results of these animal studies, together with those of human epidemiological studies $(17,23,40)$ suggest the existence of an association between glycemic control and endodontic infection. The mismatch of the results of the present study may be due to the high proportion of diabetic patients with poor glycemic control (78\%). In fact, the proportion of patients with at least one lesion of AP among poorly controlled diabetics was $47 \%$, while in well-controlled patients, it was $34 \%, 13$ points lower, but the difference was not statistically significant probably because of the high percentage of poor-controlled diabetics. A case-control design, including the same number of diabetics well- and poor-controlled, could provide more consistent data.

\section{Conclusions}

The results reveal no association of glycemic control with the prevalence of apical periodontitis or root canal treatment in diabetic patients.

\section{References}

1. Expert Committee on the Diagnosis and Classification of Diabetes Mellitus. Report of the Expert Committee on the Diagnosis and Classification of Diabetes Mellitus. Diabetes Care. 2000;23 Suppl 1:S4-19. 2. American Diabetes Association. Diagnosis and Classification of Diabetes Mellitus. Diabetes Care. 2014;37:S81-S90.

3. Montoya-Carralero JM, Saura-Pérez M, Canteras-Jordana M, Morata-Murcia IM. Reduction of HbA1c levels following nonsurgical treatment of periodontal disease in type 2 diabetics. Med Oral Patol Oral Cir Bucal. 2010;15:e808-12.

4. American Diabetes Association. Executive summary: Standards of medical care in diabetes--2010. Diabetes Care. 2010;33 Suppl 1:S4-10. 5. Eriksen HM. Epidemiology of apical periodontitis. In: Orstavik D, Ford TP, eds. Essential Endodontology: Prevention and Treatment of Apical Periodontitis. Blackwell Science. 1998:179-191.

6. Siqueira JF, Rôças IN. Present status and future directions in endodontic microbiology. Endod Top. 2014;30:3-22.

7. Caplan DJ, Chasen JB, Krall EA, Cai J, Kang S, Garcia RI, et al. Lesions of endodontic origin and risk of coronary heart disease. J Dent Res. 2006;85:996-1000.

8. Segura-Egea JJ, Martín-González J, Castellanos-Cosano L. Endodontic medicine: connections between apical periodontitis and systemic diseases. Int Endod J. 2015;48:933-951.
9. Segura-Egea JJ, Castellanos-Cosano L, Machuca G, López-López J, Martín-González J, Velasco-Ortega E, et al. Diabetes mellitus, periapical inflammation and endodontic treatment outcome. Med Oral Patol Oral Cir Bucal. 2012;17:e356-61.

10. Segura-Egea JJ, Jiménez-Pinzón A, Ríos-Santos J V, Velasco-Ortega E, Cisneros-Cabello R, Poyato-Ferrera M. High prevalence of apical periodontitis amongst type 2 diabetic patients. Int Endod J. 2005;38:564-569.

11. López-López J, Jané-Salas E, Estrugo-Devesa A, Velasco-Ortega E, Martín-González J, Segura-Egea JJ. Periapical and endodontic status of type 2 diabetic patients in Catalonia, Spain: A cross-sectional study. J Endod. 2011;37:598-601.

12. Fouad AF, Burleson J. The effect of diabetes mellitus on endodontic treatment outcome: data from an electronic patient record. J Am Dent Assoc. 2003;134:43-51; quiz 117-118.

13. Ferreira MM, Carrilho E, Carrilho F, Marques-Ferreira M, Carrilho E, Carrilho F. Diabetes mellitus and its influence on the success of endodontic treatment: a retrospective clinical study. Acta Med Port. 2014;27:15-22.

14. Marotta PS, Fontes TV, Armada L, Lima KC, Roças IN, Siqueira JF. Type 2 diabetes mellitus and the prevalence of apical periodontitis and endodontic treatment in an adult brazilian population. J Endod. 2012;38:297-300.

15. Mesgarani A, Eshkevari N, Ehsani M, Khafri S, Nafarzade S, Damankesh Z. Frequency of odontogenic periradicular lesions in diabetic patients. Casp J Intern Med. 2014;5:22-25.

16. Arya S, Duhan J, Tewari S, Sangwan P, Ghalaut V, Aggarwal S. Healing of Apical Periodontitis after Nonsurgical Treatment in Patients with Type 2 Diabetes. J Endod. 2017;43:1623-1627.

17. Smadi L. Apical Periodontitis and Endodontic Treatment in Patients with Type II Diabetes Mellitus: Comparative Cross-sectional Survey. J Contemp Dent Pract. 2017;18:358-362.

18. Nagendrababu V, Segura-Egea JJ, Fouad AF, Pulikkotil SJ, Dummer P. Association between diabetes and the outcome of root canal treatment in adults: An umbrella review. Int Endod J. 2020;53:455466.

19. Cabanillas-Balsera D, Martín-González J, Montero-Miralles P, Sánchez-Domínguez B, Jiménez-Sánchez MC, Segura-Egea JJ. Association between diabetes and nonretention of root filled teeth: a systematic review and meta-analysis. Int Endod J. 2019;52:297-306.

20. Segura-Egea JJJ, Martín-González J, Cabanillas-Balsera D, Fouad AFAF, Velasco-Ortega E, López-López J. Association between diabetes and the prevalence of radiolucent periapical lesions in root-filled teeth: systematic review and meta-analysis. Clin Oral Investig. 2016;20:1133-1141.

21. Bender IB, Seltzer S, Freedland J. The relationship of systemic diseases to endodontic failures and treatment procedures. Oral Surg Oral Med Oral Pathol. 1963;16:1102-1115.

22. Bender IB, Bender a B. Diabetes mellitus and the dental pulp. J Endod. 2003;29:383-389.

23. Sánchez-Domínguez B, López-López J, Jané-Salas E, Castellanos-Cosano L, Velasco-Ortega E, Segura-Egea JJ. Glycated hemoglobin levels and prevalence of apical periodontitis in type 2 diabetic patients. J Endod. 2015;41:601-606.

24. Cheraskin E, Ringsdorf WM. The biology of the endodontic patient. 3. Variability in periapical healing and blood glucose. J Oral Med. 1968;23:87-90

25. American Diabetes Association. 2. Classification and Diagnosis of Diabetes: Standards of Medical Care in Diabetes-2019. Diabetes Care. 2019;42(Suppl 1):S13-S28.

26. Machtet EE, Christersson LA, Grossi SG, Dunford R, Zambon JJ, Genco RJ. Clinical criteria for the definition of "established periodontitis." J Periodontol. 1992;63:206-214.

27. Orstavik D, Kerekes K, Eriksen HM, Ørstavik D. The periapical index: A scoring system for radiographic assessment of apical periodontitis. Dent Traumatol. 1986;2:20-34.

28. Castellanos-Cosano L, Machuca-Portillo G, Sánchez-Domínguez B, Martín-González J, Torrés-Lagares D, López-López J, Segura-Egea JJ. Prevalence of apical periodontitis and frequency of root canal treat- 
ment in liver transplant candidates. Med Oral Patol Oral Cir Bucal. 2013; 18:e773-e779.

29. López-López J, Jané-Salas E, Martín-González J, Castellanos-Cosano L, Llamas-Carreras JM, Velasco-Ortega E, et al. Tobacco smoking and radiographic periapical status: A retrospective case-control study. J Endod. 2012;38:584-588.

30. López-López J, Castellanos-Cosano L, Estrugo-Devesa A, Gómez-Vaquero C, Velasco-Ortega E, Segura-Egea JJ. Radiolucent periapical lesions and bone mineral density in post-menopausal women. Gerodontology. 2015;32:195-201.

31. Segura-Egea JJ, Jiménez-Pinzón A, Ríos-Santos JV, Velasco-Ortega E, Cisneros-Cabello R, Poyato-Ferrera MM. High prevalence of apical periodontitis amongst smokers in a sample of Spanish adults. Int Endod J. 2008;41:310-316.

32. Castellanos-Cosano L, Machuca-Portillo G, Sánchez-Domínguez B, Torrés-Lagares D, López-López J, Segura-Egea JJ. High prevalence of radiolucent periapical lesions amongst patients with inherited coagulation disorders. Haemophilia. 2013;19:110-115.

33. Khalighinejad N, Aminoshariae A, Kulild JC, Mickel A. Apical Periodontitis, a Predictor Variable for Preeclampsia: A Case-control Study. J Endod. 2017;43:1611-1614.

34. Poyato-Borrego M, Segura-Sampedro JJ, Martín-González J, Torres-Domínguez Y, Velasco-Ortega E, Segura-Egea JJ. High Prevalence of apical periodontitis in patients with inflammatory bowel disease: an age- and gender- matched case-control study. Inflamm Bowel Dis. 2020;26:273-279.

35. Kumar G, Tewari S, Sangwan P, Tewari S, Duhan J, Mittal S. The effect of an intraorifice barrier and base under coronal restorations on the healing of apical periodontitis: a randomized controlled trial. Int Endod J. 2020;53:298-307.

36. Nardi C, Calistri L, Pradella S, Desideri I, Lorini C, Colagrande S. Accuracy of Orthopantomography for Apical Periodontitis without Endodontic Treatment. J Endod. 2017;43:1640-1646.

37. Kadesjö N, Lynds R, Nilsson M, Shi X-Q. Radiation dose from $\mathrm{X}$-ray examinations of impacted canines: cone beam CT vs two-dimensional imaging. Dentomaxillofac Radiol. 2018;47:20170305.

38. Britto LR, Katz J, Guelmann M, Heft M. Periradicular radiographic assessment in diabetic and control individuals. Oral Surg Oral Med Oral Pathol Oral Radiol Endod. 2003;96:449-452.

39. Falk H, Hugoson A, Thorstensson H. Number of teeth, prevalence of caries and periapical lesions in insulin-dependent diabetics. Scand J Dent Res. 1989;97:198-206.

40. Sisli SN. Evaluation of the relationship between type ii diabetes mellitus and the prevalence of apical periodontitis in root-filled teeth using cone beam computed tomography: an observational cross-sectional study. Med Princ Pract. 2019;28:533-538.

41. Estrela C, Bueno MR, Azevedo BC, Azevedo JR, Pécora JD. A new periapical index based on cone beam computed tomography. J Endod. 2008;34:1325-1331.

42. Nagendrababu V, Segura-Egea J, Fouad A, Pulikkotil S, Dummer P. Association between diabetes and the outcome of root canal treatment in adults: An umbrella review. Int Endod J. 2020;53:455-46.

43. Segura-Egea JJ, Martín-González J, Cabanillas-Balsera D, Fouad AF, Velasco-Ortega E, López-López J. Association between diabetes and the prevalence of radiolucent periapical lesions in root-filled teeth: systematic review and meta-analysis. Clin Oral Investig. 2016;20:1133-1141.

44. Cabanillas-Balsera D, Martín-González J, Montero-Miralles P, Sánchez-Domínguez B, Jiménez-Sánchez MC, Segura-Egea JJ. Association between diabetes and nonretention of root filled teeth: a systematic review and meta-analysis. Int Endod J. 2019;52:297-306.

45. Iwama A, Nishigaki N, Nakamura K, et al. The effect of high sugar intake on the development of periradicular lesions in rats with type 2 diabetes. J Dent Res. 2003;82:322-325.

46. Garber SE, Shabahang S, Escher AP, Torabinejad M. The effect of hyperglycemia on pulpal healing in rats. J Endod. 2009;35:60-62. 47. Cintra LTA, Samuel RO, Facundo ACS, et al. Relationships between oral infections and blood glucose concentrations or HbAlc levels in normal and diabetic rats. Int Endod J. 2014;47:228-237.

\section{Funding}

This research received no specific grant from any funding agency in the public, commercial, or not- for- profit sectors.

\section{Conflict of interest}

The authors declare that they have no conflict of interest. 